\title{
Acontecimientos del Plan Ceibal. Una compleja trama de mediaciones soportando la apuesta inclusiva
}

\author{
Alicia Kachinovsky 1 (1) @ \\ Joaquín Paredes-Labra ${ }^{2}$ (D) @ \\ Michel Dibarboure Reynes'10@ \\ ${ }^{1}$ Universidad de la República, Uruguay; ${ }^{2}$ Universidad Autónoma de Madrid (UAM), España
}

Resumen. En el marco de un proyecto sobre el impacto del Plan CEIBAL en los procesos de inclusión social de familias beneficiadas por el modelo 1 a 1 de integración de tecnología, se procura ilustrar la multicausalidad del fenómeno estudiado. Para ello se detallan algunas vicisitudes de la relación con el saber de una escolar con la que se trabajó. En ella se pone de manifiesto la pluralidad de determinantes de las modificaciones operadas en su subjetividad y posicionamiento frente a lo escolar. La potencia de la dimensión subjetiva para producir cambios educativos se articula con el deseo de saber y éste con el deseo de saber del otro significativo.

Se trata de un estudio de casos de tipo instrumental, de una investigación cualitativa afiliada al enfoque clínico de investigación en ciencias humanas, que privilegia como instrumentos de indagación los dispositivos conversacionales. El análisis del material discursivo recogido pone de relieve el impacto del Plan CEIBAL en la vida escolar del caso en cuestión y el conjunto de condicionantes personales e institucionales que lo han hecho posible. Entre los hallazgos, se destaca la detección de una cadena de mediadores humanos, solidarios entre sí, que hacen posible la accesibilidad a la tecnología.

Palabras clave: Plan Ceibal; inclusión educativa; mediadores; subjetividad.

Acontecimentos do Plano Ceibal. Uma complexa trama de mediações que apoia a aposta inclusiva

Resumo. No âmbito de um projeto sobre o impacto do Plano CEIBAL nos processos de inclusão social de famílias beneficiadas pelo modelo 1 a 1 de integração tecnológica, busca-se ilustrar a multicausalidade do fenômeno estudado. Para isso, especificamse algumas vicissitudes da relação com o conhecimento de uma estudante com a qual desenvolveu-se o estudo. Nela identifica-se a pluralidade de determinantes das mudanças realizadas em sua subjetividade e posicionamento em relação ao ambiente escolar. O poder da dimensão subjetiva de produzir mudanças educacionais articulase com o desejo de conhecer e este, por sua vez, com o desejo de conhecer outro significado.

Trata-se de um estudo de caso de tipo instrumental de uma pesquisa qualitativa orientada para uma abordagem clínica de investigação em ciências humanas. Tal estudo privilegia os dispositivos conversacionais como instrumentos de indagação. A análise do material discursivo que foi coletado destaca o impacto do Plano CEIBAL na vida escolar do caso em questão e o conjunto de condições pessoais e institucionais que o tornaram possível. Um dos resultados mais salientes é a detecção de uma cadeia de mediadores humanos, solidários uns com os outros, que possibilitam o acesso à tecnologia.

Palavras-chave: Plano Ceibal; inclusão educacional; mediadores; subjetividade.

Events of the Ceibal Plan. A complex web of mediations supporting the inclusive defy Abstract. Within the framework of a project to assess the impact of Plan CEIBAL on the processes of social inclusion of families benefited by the 1 to 1 model of technology integration, the aim of this paper is to illustrate the multicausality of the phenomenon studied. For this purpose, some vicissitudes of the student's relationship with knowledge are detailed. The plurality of determining factors in the changes operated in her subjectivity and positioning towards school is revealed. The power of the subjective dimension to produce educational changes is articulated with the desire to know, and this in turn is connected to the other's desire for knowledge.

This is a case study of instrumental type. It is also qualitative research affiliated with the clinical approach of research in human sciences, which privileges conversational 
devices as instruments of inquiry. The analysis of the discursive material collected highlights the impact of Plan CEIBAL on the school life of the student case and the set of personal and institutional conditions that have made it possible. Among the findings is the detection of a chain of human mediators, in solidarity with each other, who make access to technology possible.

Keywords: Ceibal Plan; educational inclusion; mediators; subjectivity.

\section{Introducción}

«"En el marco del proyecto "Exclusión, pobreza y TIC en las escuelas de América Latina y España", proyecto CEAL-AL/2015-31 financiado por la $9^{a}$ convocatoria de proyectos de cooperación Interuniversitaria UAM-Santander con América Latina. Resolución de 19 de junio de 2015», un grupo de investigadores de la Universidad de la República llevó a cabo en Uruguay un estudio que tuvo como objetivo valorar el impacto del Plan CEIBAL en los procesos de inclusión social de familias beneficiadas por el modelo 1a1 de integración de tecnología, situadas en contextos de exclusión y pobreza: una investigación de carácter exploratorio-descriptivo, organizada en torno a un pequeño número de casos (seis familias con las que se trabajó en cada una de las dos escuelas seleccionadas). Las presentes reflexiones se circunscriben a una de las familias estudiadas y rescatan el encuentro con una de sus integrantes, una chica de 14 años que será mencionada como Victoria. Se procura mostrar la sobredeterminación del fenómeno estudiado, es decir, la pluralidad de factores determinantes de los cambios operados en su subjetividad y posicionamiento frente a lo escolar. Un complejo interjuego de variables, solidarias entre sí, producen cambios sustantivos en la protagonista de este artículo. En ella parece haber un antes y un después del CEIBAL.

El Plan CEIBAL constituye un ejemplo paradigmático de inversión social, a cuenta de la institución educativa. Con el propósito de incluir a Uruguay en la sociedad del conocimiento, entre 2007 y 2009 el gobierno uruguayo puso en marcha el Plan CEIBAL, otorgando a cada niño y respectivos docentes de escuelas públicas de todo el territorio nacional una computadora portátil (modelo 1 a 1 ) y acceso a Internet en los centros escolares y otros espacios públicos. Más tarde se extendió a enseñanza media. Desde sus orígenes fue un proyecto de carácter socioeducativo, cuyo objetivo inmediato consistió en abatir la brecha digital entre los distintos estratos sociales, pensado como vía regia para minimizar en el mediano plazo la brecha social. Tal aventura humana convirtió a este pequeño país en la primera experiencia mundial de cobertura total, al dotar a todos los niños, adolescentes y docentes de enseñanza primaria y media pública de una computadora personal, conocida inicialmente como Ceibalita o XO. En tanto política pública, el Plan CEIBAL se inspira en la idea presentada al Foro Mundial de Davos, en 2005, 
por Nicholas Negroponte. Su propósito era garantizar el acceso y utilización universal de las Tecnologías de la Información y la Comunicación (TIC) a través de la creación de dispositivos de bajo costo.

Una expectativa esperanzada impulsaba el desafío asumido por Uruguay, sin que ello supusiera un determinismo tecnológico según el cual la mera disponibilidad de un potente dispositivo tecnológico llevaría a convertir a los niños de pasivos consumidores de información producida por otros a creadores de conocimiento. Por el contrario, se entendió desde un principio que la computadora por sí sola no modificaría la calidad de los aprendizajes escolares o la calidad de vida de sus ciudadanos. El éxito de tal inversión dependía de estrategias institucionales complementarias y de acciones humanas muy diversas que era preciso indagar y precisar.

El Plan CEIBAL ha contado con el apoyo de un fuerte liderazgo político de la Presidencia de la República y un liderazgo técnico del Laboratorio Tecnológico del Uruguay (LATU). Ha tenido garantías institucionales y presupuestales que le han permitido permanecer hasta la fecha (Vaillant, 2013). A estos factores facilitadores se contrapusieron tres obstáculos: el rol secundario adjudicado inicialmente al cuerpo docente en la decisión política asumida, la insuficiente formación de los educadores en habilidades propias de la tecnología educativa y los temores por los cambios que se sospecha habrían de ocurrir en la relación saber/poder entre maestros y aprendices.

Sin desconocer la importancia de los insumos materiales para el aprendizaje, entre los cuales se destaca el dispositivo tecnológico entregado por el Plan CEIBAL, la hipótesis de trabajo a sostener consiste en la potencia de la dimensión subjetiva para producir cambios educativos, dimensión que compromete a los diferentes actores del escenario en cuestión.

\section{Marco teórico}

Una de las tendencias más fuertes de la sociedad del conocimiento es el aumento de las desigualdades sociales (De Sousa Santos, 2010). La ruptura del círculo vicioso de la pobreza requiere de intervenciones oportunas en etapas tempranas de la vida, donde se establecen las bases del capital cognitivo humano. Ello implica el trabajo con primera infancia y respectivas familias, sin descuidar acciones destinadas a la igualación de oportunidades en etapas posteriores. 
La educación es considerada un factor inclusivo, porque ofrece a los individuos la posibilidad de desarrollar aquellas competencias básicas indispensables para introducirse en la vida social: conocimientos, habilidades, actitudes y valores. El concepto de inclusión social ha sido aquí adoptado en un sentido amplio, como todo aquello que contribuye a instaurar o fortalecer el lazo social, a corto o mediano plazo, en entornos micro y macrosociales. El acceso a diversas instituciones y circuitos sociales constituye un aspecto medular del problema. Por eso, desde una perspectiva de derechos, la exclusión social en la infancia condiciona un eventual bienestar futuro, ya que no se desarrollarán aquellas habilidades que luego condicionarán la capacidad de incorporación al mercado laboral, a la sociedad y a la vida ciudadana (Sen, 1992, 2000). El fracaso escolar es, en tal sentido, una forma de exclusión social temprana.

A pesar de la íntima relación entre las variables socioeconómicas y las educativas, algo más recientemente empezó a hacerse visible que la desigualdad social, si bien es una parte sustantiva de la explicación sobre los problemas escolares, no es toda la explicación. Y aunque la tecnología se ha convertido en uno de esos talismanes capaces de resolver todos los males de la educación (Sánchez-Antolín \& Paredes-Labra, 2014), una creciente valorización de la subjetividad permite hoy reabrir el debate sobre las nuevas desigualdades de las que se habla. Estas desigualdades resultan ahora bastante más difíciles de admitir, porque ponen en crisis la representación que cada individuo tiene de sí mismo. Mientras los efectos biológicos son con frecuencia reparables debido a la plasticidad del cerebro humano, los efectos atribuibles a la representación subjetiva del trauma provocado por el discurso académico, por ejemplo, pueden ser mucho más renuentes y lentos de restaurar. Las cicatrices resultantes de aquellas agresiones motivadas por estigmas sociales, resistentes al cambio, requieren de un trabajo "contracultural". Si éste se desarrolla en un clima de confianza, compromiso y afectividad, permitirá rectificar estereotipos y prejuicios. Por ello la importancia que revisten las actitudes docentes en la consecución de logros o fracasos escolares (Tedesco, 2014).

Por otra parte, analizar los problemas escolares sin someterse al clásico concepto de aprendizaje y a sus lazos filiatorios, permite descentrar la cuestión de lo meramente cognitivo e ingresar en el complejo tema de los procesos de simbolización. La pregunta se aloja entonces alrededor de la relación con el saber (R/S) -una noción de origen francés, que data de la década de 1980-, cuestionando el vínculo más o menos estable que un sujeto singular o colectivo establece con el objeto de conocimiento. 
Desde esta perspectiva teórica, aprender es apoderarse de algo que originariamente no es propio, comprometiendo al sujeto a relacionarse con el afuera, con lo ajeno. Si bien ello implica una ganancia, aprender es también declinar: perder para incorporar lo nuevo, renuncia o micro duelo al ser anterior (Ogden, 1992).

Cuando la relación con el saber se circunscribe al lenguaje, es preciso dar cuenta de la complejidad derivada de su doble función: el lenguaje es un objeto de conocimiento en sí mismo y es, al mismo tiempo, el medio privilegiado de aproximación a los más variados objetos de conocimiento. El lenguaje preexiste al sujeto, y antes que la criatura humana pueda hablar estará inmersa en un "baño de lenguaje", que lo anticipa como ciudadano de la cultura y subcultura de procedencia. En este "baño del lenguaje" el sujeto se ubicará en el lugar que le sea asignado, y allí se reconocerá. Poco tiempo después los maestros, como representantes del espacio escolar, tomarán a su cargo la tarea de ensanchar y diversificar el escenario lingüístico. Sin embargo, mientras los maestros apelan a un código lingüístico elaborado, los niños que provienen de medios sociales carenciados detentan un código lingüístico restringido (Bernstein, 1988 y 1989), herencia del medio en el cual han crecido. El surtido lexical y sintáctico de los docentes es muy distinto al de los modelos identificatorios familiares, y esto constituye para algunos un motivo de extrañamiento, tornando al medio escolar en un espacio poco amigable. Su ajenidad para niños como Victoria determina respuestas de distanciamiento hacia el conocimiento transmitido.

El nivel de proximidad o distanciamiento subjetivo del saber de cualquier sujeto responde siempre a posiciones relativas, que no tienen que ver necesariamente con lo que un sujeto efectiva y objetivamente sabe de algo, sino de lo que cree saber. Se trata de creencias o convicciones, que forman parte del sentimiento de sí de cada persona. Frente al objeto de conocimiento todo sujeto adopta dos posiciones subjetivas básicas que es posible inferir: saber o no saber. En una misma persona estas dos posiciones suelen presentar una singular alternancia, aunque es posible determinar un predominio relativo de una sobre otra. Luego es posible establecer matices dentro de una y otra posición, de donde emergen las cuatro categorías siguientes:

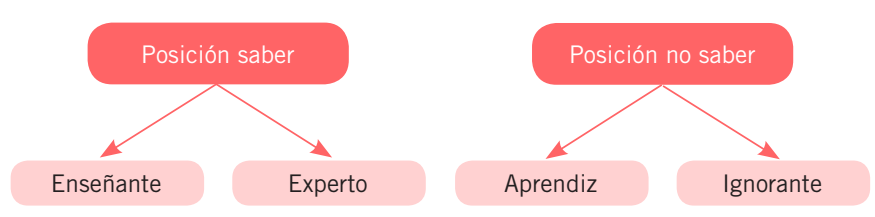


El enseñante es un representante del saber. Detenta un supuesto saber sobre algo, que procura mostrar o transmitir, en el entendido que el saber es un bien que circula y no es propiedad exclusiva de nadie. El enseñante explica, enseña, demuestra, orienta, ordena, corrige y señala errores.

La reiteración o prevalencia de la posición de enseñante en un mismo niño, joven o adulto puede dar cuenta de un grado de apropiación imaginaria del saber próximo al del experto. En este otro polo de la posición saber, el experto exhibe un saber absoluto e incuestionable, que se presenta como exceso de saber. Mientras que el enseñante sostiene su decir basado en creencias, el experto ampara su discurso en supuestas certezas.

Aprendiz e ignorante comparten la posición de no saber sobre el mundo y sobre el sí mismo. En el aprendiz, el reconocimiento de su ignorancia o su saber en falta, lo impulsa a una búsqueda activa de lo no sabido: pregunta, consulta, ensaya, explora, curiosea. El ignorante, en cambio, adopta una posición pasiva. No cree en su potencialidad de aprendiente, en tanto ubica el saber imaginariamente como posesión exclusiva y excluyente de determinados personajes (Kachinovsky, 2016).

\section{Caracterización metodológica}

Se trata de un estudio de casos de tipo instrumental (Stake, 2005 y 2007), ya que el interés se concentra en un problema conceptual y empírico más amplio que los casos en cuestión. Es además una investigación cualitativa, afiliada al enfoque clínico de investigación en ciencias humanas, que procura aproximarse a la singularidad de dicho problema en profundidad. Por tal motivo los instrumentos privilegiados fueron dispositivos conversacionales, que más allá de simples datos permiten construir una red de información. Los hallazgos alcanzados son entonces una coproducción entre investigadores e investigados.

La estrategia diseñada contempló un pequeño número de casos (seis familias en cada una de las dos escuelas seleccionadas), en virtud del carácter exploratorio-descriptivo de esta investigación. La selección de las familias con las que se trabajó durante cuatro meses aproximadamente, no se orientó por la exigencia de generalizar los resultados sino por la necesidad de que sus características fueran apropiadas para responder las preguntas de la investigación y pudieran colaborar a comprender otros casos similares (Kazez, 2009). Obedeció a los criterios aportados por los investigadores y a las sugerencias de los docentes involucrados. Se entrevistó al personal docente y no docente (directora, maestra de sexto año, maestras comunitarias 
y auxiliares de servicio) y a los adultos referentes de las respectivas familias. Con los niños se utilizaron técnicas específicas de exploración psicológica. Se apeló a técnicas utilizadas en ocasión de tempranas investigaciones sobre los impactos producidos por la implementación del Plan CEIBAL en el Uruguay (Kachinovsky et al., 2013). Dichas técnicas resultan de la adaptación de herramientas de evaluación psicológica, de filiación clínica, cuya ventaja adicional es la de ser menos sensibles a los discursos sociales imperantes. Se adoptan así, como instrumentos de recolección de información: a) la "Entrevista con la XO", inspirada en la entrevista de juego psicoanalítica, que sustituye la tradicional caja de juegos por la ceibalita o XO (nombres adjudicados a la laptop del P. CEIBAL); b) el TIC -TAT, una técnica proyectiva temática basada en la prueba de Apercepción Temática (Murray, 1979) y en el Cuestionario Desiderativo (Celener y Guinzbourg, 2009). Se ofrecen estímulos visuales ambiguos o poco estructurados (láminas) para que el niño los perciba y estructure de acuerdo con sus temores, conflictos, deseos, etcétera.

El presente artículo se focaliza en el análisis del material verbal de una única persona -una escolar con extra-edad, integrante de una de las familias con las que se trabajó-, en consideración al valor didáctico y heurístico de dicho material. La relación entre los observables y su interpretación estuvo sostenida por mediaciones teóricas de orden complejo, extraídas en su mayoría del corpus teórico del Psicoanálisis. Para ello se diseñaron dimensiones conceptuales de análisis apriorísticas o ejes temáticos que organizaron la tarea interpretativa. Se construyeron asimismo categorías analíticas emergentes (Cisterna, 2005).

\section{El contexto: entorno social y local escolar}

La escuela se inserta en un barrio periférico de la ciudad de Montevideo, poblado preferentemente por familias de bajos ingresos. Se trata de una población joven y extremadamente vulnerable, con bajo clima educativo. La población se inserta tempranamente en el mundo del trabajo, sin suficiente formación e información al respecto, en trabajos precarios, de bajos salarios y malas condiciones laborales, con dificultades para ejercer sus derechos.

El centro educativo en cuestión es una escuela pública que funciona en doble horario ( 8.00 a 12.00 horas y 13.00 a 17.00 horas), a la que concurren aproximadamente 400 niños entre los dos turnos. El conjunto del paisaje escolar es sencillo, de pequeñas dimensiones, equipado con lo mínimo necesario, pulcro y agradable. Los salones de clase están equipados con mobiliario en malas condiciones. La calle de acceso está asfaltada, pero 
no hay veredas pavimentadas a sus costados. La entrada es precaria, con un acceso de hormigón en mal estado y rejas con cobertores que impiden visualizar hacia el interior del patio de acceso.

\subsection{Victoria, un antes y un después del CEIBAL}

\subsubsection{Presentación de Victoria}

Victoria concurre al centro escolar antes descripto. La joven vive con sus padres adoptivos y tres hermanos. Cursa sexto año por primera vez. Al comenzar la entrevista confiesa haber repetido tres veces, refiriéndose a cursos anteriores. Luego afirma con seguridad: "Así que ahora me puse las pilas porque quiero entrar al liceo ya". Luego agrega con renovada firmeza: "Tengo 14, voy a entrar con 15 al liceo, pero no me importa".

\subsubsection{Vicisitudes de la Relación con el Saber}

\section{Posición saber}

Lo más destacable de esta entrevista tiene que ver con el cambio de posición subjetiva frente al saber operado en Victoria, es decir, su relación con el objeto de conocimiento a título de posesión imaginaria. Antes que el Plan CEIBAL pasara a formar parte de su cotidianeidad, Victoria no podía asumir su condición de aprendiz. Habitaba a reiteración una posición de ignorante. He aquí un elocuente autorretrato: "Cuando la maestra explicaba yo miraba para allá y para acá y no prestaba atención. Yo estaba media dispersa y eso. Estaba pensando en otras cosas y hablaba con mis amigas y eso". Por el contrario, ya en los primeros minutos de la entrevista, Victoria prende su computadora y le enseña a la entrevistadora cómo hacer un libro con un programa que aprendió a usar en clase:

Mirá, vas a herramientas... [muestra lo que hace] vas a herramientas. Esto es un libro al parecer... Después vas acá [indica en su XO], y te aparece esto para hacer más hojas o también le podés sacar. Primero, si vos querés ponerle color, elegís cualquiera.

La entrevistadora escucha y acompaña la entusiasta exposición magistral de Victoria (posición enseñante) con periódicas interjecciones de interés o asombro, que consiguen un mayor despliegue del campo discursivo:

Y si vas a herramientas... texto... ahí escribís lo que quieras, en cualquier color. Y después si vos querés subrayarlo, hacés una línea o podés sacarla también. 


\section{Posición no saber}

Si bien es posible afirmar que la posición saber es la modalidad de relacionamiento dominante a lo largo de la entrevista, ello no implica que no se haga presente la posición no saber, como cuando dice:

La maestra lo había explicado, pero yo no lo había entendido. Viste... yo no entiendo casi nada.

Este particular pronunciamiento sobre no entender casi nada la posiciona en el circuito de la ignorancia. ¿Es ésta otra cara de la verdad de Victoria o es simplemente su verdad, en el sentido de lo más arraigado y estable? Adoptar el concepto de identidad narrativa acuñado por Paul Ricoeur (1996), con sus visos de permanencia (mismidad) y cambio o movimiento (ipseidad), resulta un modo de entender esta persistencia en el lugar de no saber - ignorante. La identidad no es para el filósofo francés una esencia (invariante) determinada por hechos pretéritos ni una condición coagulada del ser, lo que induce a explorar alternativas como el Plan CEIBAL que procuren resignar el "proyecto identificatorio" (Aulagnier, 1977; Prol, 2004) y quebrantar la "clausura identitaria" (Enriquez, 1993). Desde esta perspectiva, su afirmación constituye apenas una arista de su ipseidad. Otra forma de entender el contraste entre estas dos versiones del ser (enseñante - ignorante) consiste en admitir su coexistencia, así como su eventual emergencia y alternancia, a condición de concebir el psiquismo como un sistema abierto y heterogéneo en cuanto a sus contenidos (Green, 1996).

Recurrir a otro pasaje de esta misma entrevista permite complejizar la pregunta anterior, porque remite al problema del capital simbólico disponible, los códigos lingüísticos y las marcas de clase, tres aspectos íntimamente relacionados que suelen impactar sobre el sentimiento de sí de los aprendices. Victoria no constituye una excepción al respecto. Desde el comienzo muestra un repertorio semántico reducido y un fuerte grado de previsibilidad morfosintáctica. Sin embargo, cuando necesita ejemplificar cómo trabajan en la clase con el dispositivo tecnológico investigado, la ceibalita, brinda una definición muy precisa del concepto de "longitud". Es lícito preguntarse por el grado de apropiación de dicho enunciado. En tanto parece ser un concepto memorizado, es pensado como palabra ajena (Bajtín, 1990) a dilucidar; es preciso indagar cuál es el grado de comprensión de lo manifestado, ya que podría ser no más que una copia servil de lo que está escrito en algún libro o de lo que ha dicho la maestra. Para sorpresa de la entrevistadora, al propiciar un mayor desarrollo de la definición brindada, Victoria responde con suficiente solvencia, recurriendo ahora a un código elaborado al que parecía no haber accedido. Su interés indeclinable en transmitir la nueva experiencia escolar provoca renovado desconcierto en quien la escucha: 
Victoria: La maestra nos mostró todo lo que tiene -imágenes, vídeo, en el pizarrón- para que nos entre en la cabeza. Ahora estoy estudiando lo que es la Tierra y eso, que lo tenemos también que explicar. Hoy me toca pasar con mi grupo al oral.

Entrevistadora: ¿Y estás nerviosa?

Victoria: Sí, es como que paso y ya me olvido de todo.

Para quienes han trabajado en contextos sociales vulnerables, la expresión "para que nos entre en la cabeza" ha de resultarles familiar. Es frecuente que las madres de estos medios sociales afirmen que a sus hijos las letras o los números no les entran en la cabeza. Denota una marca social que no le es ajena a la joven entrevistada. El verbo "entrar" es pensado aquí como un cuerpo extraño, que violenta al otro, del orden de la intromisión (Laplanche, 1996). No da cuenta de algo integrado, pasible de ser usado; tampoco da cuenta de un sentimiento de pertenencia característico de lo aprendido, y así como entra sale ("me olvido de todo"). Aunque se admita que ha sido Foucault (1992) quien desarrolló con particular agudeza la clásica relación saber/poder, quizá Victoria como tantos otros no requiera tanta erudición para reconocer las diferencias sociales en torno a la posesión del saber. Se actualiza así la fantasía de que el saber está en otro lugar o le pertenece a otro, como efecto de la representación singular de los traumatismos provocados por la mirada y el discurso social (Tedesco, 2014), entre los cuales debe jerarquizarse en este caso una vasta historia de repetición escolar. La fijeza de estos férreos determinismos sociales y educativos se traducen en un sentimiento de sí depreciado (Kachinovsky, A., Dibarboure, M. y Paredes-Labra, J., 2017), engrosando las filas de los desposeídos del saber, en un contexto en que el conocimiento representa un valor de consumo.

Investirse a sí misma en calidad de aprendiente, confiar en su potencial capacidad de aprehender el objeto de conocimiento, no parece haber sido una opción viable hasta ahora, hasta ingresar a sexto año. En este nuevo contexto aprender parece ser algo posible, como puede apreciarse en una de sus intervenciones en las que se pregunta por un eventual envío de sus producciones a la entrevistadora: “¿Por Gmail decís? Ah, eso no entendí todavía... pero ya lo estamos viendo". El gerundio empleado para el verbo "ver" (estamos viendo) alude a un proceso de aproximación al objeto de conocimiento en el cual se la percibe comprometida. Si bien declara no haber entendido, lo cual la ubica en posición de no saber, el uso del adverbio "todavía" modaliza la sentencia: Ileva a suponer que dicha situación persiste, pero cambiará o es factible que cambie en el futuro, ubicando a Victoria en posición de aprendiz (no de ignorante). Y esta perspectiva esperanzada es condición inexcusable para que se afiance la identidad de aprendiz. 


\subsubsection{Construcción de la Relación con el Saber}

\section{Deseo de saber, deseo del otro}

A continuación, se analiza en qué circunstancias se produce este tránsito bidireccional desde una posición subjetiva a otra (no saber $\leftrightarrow$ saber; ignorante $\leftrightarrow$ aprendiz; etc.), con la expectativa de arribar, a partir de este único caso, a conclusiones que colaboren a esclarecer otros casos. En primer término, si la R/S se origina en el deseo de saber, ¿qué indicios arroja el discurso de Victoria que permitan inferir cómo ocurre esto en ella?

El deseo del otro se presenta como un elemento clave para que se Ileve a cabo esta travesía. Cuando se le pregunta si anteriormente ella estuvo de acuerdo con recursar, devela la posición materna hacia el saber: "Sí, porque no entendí nada. Repetir es por mi madre; ella quiere que aprenda más. Ahora me pongo las pilas, le muestro lo que hago, lo que hice en los libros y ta...". La madre es, en esta oportunidad, ese otro significativo a quien se quiere complacer, al modo de una ofrenda de amor. El deseo del otro significativo antecede y condiciona el propio deseo; el otro es prioritario (Laplanche, 1996). Además, en la frase "ella quiere que aprenda más" se evidencia no solo el deseo materno proyectándola como aprendiz, sino el mensaje implícito de que ello es posible, su ilusión y voto de confianza en las potencialidades de Victoria. No obstante, cabe preguntarse por qué su actitud anterior, por qué el cambio no se produjo antes o por qué sintió que no podía complacer a su madre antes. La respuesta a dicha interrogante queda asociada al nuevo contexto escolar y personal que atraviesa Victoria, en el que se han movido algunas piezas.

En cuanto al primero, el docente es asimismo un otro significativo a considerar. Su deseo apuntala y renueva el deseo materno. El cambio de actitud de Victoria hacia las tareas escolares queda indisociablemente vinculado con su ingreso a sexto y su encuentro con una maestra especial:

Victoria: Nosotros trabajamos mucho con la computadora. Desde que entramos a la escuela ya nos fue avisando la maestra de que no tenemos que olvidarnos de la computadora, porque ella trabaja mucho con la computadora, hasta fin de año.

Entrevistadora: ¡Qué bien! Y dice la maestra que vos estás muy entusiasmada...

Victoria: Sí, porque ta, la maestra nos enseñó a hacer libros de Etoys [herramienta informática de software libre]. 
Cuando se apunta a determinar el antes y después de dicha maestra y se le pregunta si ella sabía usar esa computadora que el Plan CEIBAL le había entregado al comenzar primer año, responde: "No, no sabía nada. No sabía qué era "Etoys", no sabía que existía ese programa".

Ningún otro maestro había puesto tanto entusiasmo como la maestra de sexto año, a quien otro niño había adjetivado como "digital" (Kachinovsky, A., Dibarboure, M. y Paredes-Labra, J., 2017). El testimonio de Victoria coincide con las versiones docentes recogidas en esa misma escuela por medio de entrevistas y encuentros colectivos: sus dificultades para darle un uso pedagógico a la tecnología disponible.

En cuanto al contexto personal aludido, surge la dificultad de comunicar al lector la concomitancia de situaciones acaecidas en la dramática familiar de Victoria y los cambios escolares ocurridos, sin poner en riesgo el principio de confidencialidad al que se debe cualquier tipo de investigación con seres humanos. Entonces, haciendo a un lado lo anecdótico, puede decirse que un episodio penoso revierte paradójicamente la incertidumbre sobre la permanencia de Victoria en el seno familiar de adopción, motivo de sus preocupaciones que parecía absorber gran parte de su atención. Es posible que esta pieza contextual haya colaborado fuertemente en su actitud hacia lo escolar; la situación de estabilidad alcanzada habría favorecido que ella se pusiera "las pilas".

Cuando se le pregunta qué piensa sobre haber tenido que recursar más de una vez, explica: "No sabía casi nada, como que iba a pasar a la ligera, así... sin saber nada". Entonces se le pide una hipótesis sobre su dificultad, es decir, que explique por qué no sabía "casi nada" o por qué no aprendía, a lo que responde: "No sé, me costaba más seguir, me costaba prestar atención, me costaba un montón de cosas". La conjetura del anudamiento del síntoma (labilidad atencional) a la compleja circunstancia personal referida no deriva del discurso de Victoria sino del discurso de su maestra y de su "madre de crianza", como ella la llama, recabados en las respectivas entrevistas.

\section{Deseo del otro, deseo de saber}

Para que se pueda establecer una relación con el saber que instituya la condición de aprendiz, éste debe ser investido por un otro significativo como sujeto del conocimiento. La madre adoptiva de Victoria cumple esa función: "Vos ahí repetís porque tenés que aprender más, no tenés que pasar así nomás." Una vez más la expresión de confianza en la capacidad de Victoria; si tiene que aprender más, es porque puede hacerlo. 
Las miradas de reconocimiento que recibe Victoria en su casa y en la escuela se potencian mutuamente. Sorprende a la entrevistadora que antes de comenzar la entrevista Victoria ya tiene su ceibalita encendida. Cuando se le pregunta por qué la prendió, lo atribuye a un encargo de su maestra y aclara: "Para mostrarles". Algunas explicaciones más llevan a inferir que ella concurre a la entrevista como una representante de su maestra, dando cumplimiento a la designación recibida. Refiriéndose a su familia, cuenta: "Les dije que me iban a hacer una entrevista y me dijeron: “QQué hiciste para que te hagan una entrevista?" Y yo les mostré y me felicitaron." Queda ubicada así en el lugar de la elegida, un buen ejemplo de discriminación positiva a la que esta investigación ha contribuido.

Habida cuenta de este reconocimiento, ¿cómo se constituye el deseo de saber? La explícita necesidad de conformar a su madre, ya mencionada, insiste luego como deseo de agradar a la entrevistadora: "El maestro preguntó qué era "modernización" y yo leí y me lo aprendí. ¿Te digo? Modernización es un proceso de sociabilización y tecnicación, a diferencia de modernidad y modernismo". Se observa una activa búsqueda de la mirada complacida del adulto, en calidad de espejo narcisizante en el cual reparar su imagen dañada. Hasta acá, sin embargo, sigue cobrando relevancia el deseo del semejante.

Otros pasajes de la entrevista revelan que aquel deseo ajeno, tal vez por vía identificatoria, ha sufrido un proceso de apropiación, como cuando afirma: "Ahora estamos trabajando en historia; me gusta la historia". O cuando exterioriza en forma espontánea: "Sí, ahora capaz que hago otro libro; voy a buscar algo para hacer. Me gusta investigar". Ese deseo de saber y ese entusiasmo por seguir descubriendo conocimientos la lleva a crear sus propias estrategias de aprendizaje, como muestra el siguiente fragmento:

Yo no sabía que [las hormigas] eran larvas y que cuando nacen se meten en un capullo y se reproducen ahí dentro y después salen. (...) Yo saco la información de acá [se refiere a la computadora] y la escribo en una cuadernola que tengo. Toda la información que busqué de acá, desde que empezamos el año y ta, saco la información, la paso para la cuadernola y después la hago en la computadora. La información de todos los libros está en esa cuadernola, me resulta más fácil hacer eso.

Victoria pone en acto una interesante concepción de Jerome Bruner (1991), sobre los procesos de adquisición del conocimiento, concebidos como acciones situadas, distribuidas y de naturaleza cultural. El profesor de Harvard sostiene así que "el conocimiento de una 'persona' no se encuentra simplemente en su cabeza, en un 'solo de persona', sino también en las anotaciones que uno ha tomado en cuadernos, en los libros 
con pasajes subrayados, en los manuales que hemos aprendido a consultar, en las fuentes de información que hemos conectado a nuestro ordenador, en los amigos a los que recurrimos y así sucesivamente" (pp. 106 y 107).

\section{Deseo de saber, proyecto de vida}

Resta por explorar cómo ha incidido el Plan CEIBAL sobre el proyecto de vida de Victoria. Frente a su gran entusiasmo por comenzar el liceo -su proyecto inmediato- se procura indagar los motivos, sin encontrar una respuesta consistente:

Porque mi hermana me cuenta todo lo que hacen allá y me gusta. (...) A mí me gusta de tarde. Que tienen doce materias, que cambian de salón a cada rato y que tenés cuarenta minutos con cada profesor y tenés un lote de recreo.

A través de estas palabras no es posible afirmar que su interés por el liceo esté mediado por su deseo de saber. Un nuevo intento por alcanzar su verdad resulta tan infructuoso como el anterior. Luego se intenta determinar el lugar de la educación en general y de la computación en particular en su proyecto de vida a mediano plazo, empleando expresiones tales como "cuando seas grande, como tu hermana la más grande". No resulta difícil imaginar los motivos que la llevan a poner el acento en la construcción de una familia propia o a tener que apelar al pronombre de la primera persona del singular: "Yo quiero tener mi casa, mis cosas, comprármelas yo misma. Y estar con mi familia. Quiero tener una nena y un varón".

En otra oportunidad agrega: "Sí, me gustaría trabajar en McDonald's. No me gustaría trabajar en limpieza, no. Me gustaría trabajar en tiendas". La entrevistadora le pregunta si alguna vez pensó en terminar el liceo y estudiar otra cosa, a lo que responde: "Me gustaría ser abogada, pero trabajar, y eso me gustaría, trabajar en una tienda. Ser abogada y trabajar en una tienda".

Parece haber en Victoria un divorcio representacional entre actividad laboral y actividad profesional ("ser abogada, pero trabajar"). Obtener un título universitario queda reservado a la esfera del "ser", al modo de una insignia identitaria, pero no es visualizado como herramienta de movilidad social.

\subsubsection{Andamiajes y alcances de la Relación con el Saber}

A Victoria le habían robado su ceibalita, pero no parecía haber interés en recuperarla. Algo distinto ocurre en virtud del comienzo de un nuevo año, con una nueva maestra: “... entonces mi padre vino a hablar y me dieron otra. Ahí la maestra empezó a hablar que le encantaba todo lo de 
la tecnología y eso. Este programa yo no lo sabía, y después lo abrí y eso, y nos explicaba dónde era con la pantalla y ta. Yo fui a mi casa y entré y eso. Yo no sabía tanto de esto; mi hermana sabía y me explicó".

He aquí nuevamente al otro, a los otros -padre, maestra, hermana-, sosteniendo el proceso de apropiación de la tecnología. Del mismo modo, cuando se le pregunta por un conjunto de creaciones que ha mostrado con evidente orgullo, plantea: "Sí, a mí me enseñó una compañera, porque yo no lo había entendido mucho". Esta compañera a la que recurre constituye un cuarto mediador. ¡Imposible determinar cuántos más habrá! Es preciso reconocer, sin embargo, que en ésta como en otras situaciones similares lo tecnológico intensifica los intercambios entre pares, robusteciendo el derecho a no saber y a solicitar la colaboración del semejante.

Otra variable, capaz de aportar comprensión sobre los cambios ocurridos, tiene que ver con el marco institucional, es decir, con el clima educativo del centro educativo del que se trate, sus prioridades, sus proyectos y su relación familia-escuela. En cierto momento se le pregunta a Victoria si la información de la que está hablando la buscó sola, para determinar el grado de autonomía detentado y el desarrollo de su juicio crítico, con miras a seleccionar la información. Entonces responde: "Sí, porque yo en mi casa no tengo Internet. Entonces, antes de irme, busco y saco captura de pantalla. Yo toda la información que saco la meto ahí, en una carpeta".

El centro educativo, que sí tiene Internet, se ha vuelto más atractivo -más deseable- para muchos niños y jóvenes uruguayos que no gozan del privilegio de poder pagarlo y tenerlo en su hogar. Es importante destacar que si el centro educativo puede brindar conectividad ello se debe a la toma de importantes decisiones políticas, que demandan acuerdos interinstitucionales -que a su vez consumen tiempo y recursos humanos-, amén de un fuerte esfuerzo económico que es dable concebir como inversión social.

En entrevistas llevadas a cabo con la directora de la escuela, se visualiza un fuerte compromiso con el Plan CEIBAL y, en especial, su aval y apoyo a las iniciativas que toman algunos docentes en este sentido. También el vínculo con las familias es fluido, lo cual justifica que el padre solicite y obtenga una segunda computadora para Victoria, cuando la primera había sido robada de su propia casa.

La entrevista con Victoria ilustra asimismo otras posibles proyecciones de este incipiente proceso, revelando los alcances de dicha mudanza. Cuando se le pregunta si sus padres de adopción usan la computadora de CEIBAL, responde: "Sí, yo les muestro las cosas que hago". Puede inferirse de sus palabras que el Plan CEIBAL representa para este grupo familiar una 
ocasión de fortalecimiento de la relación existente -siempre que haya una simiente previa-, en tanto ofrece nuevos motivos de encuentro y de diálogo. Pero además, este es un primer anticipo del supuesto impacto del plan sobre una segunda generación, que no es la directamente beneficiada. El verbo 'mostrar', sinónimo de explicar o enseñar, reconfigura el triángulo pedagógico (Beillerot, 1996), asignándole a Victoria el lugar de enseñante, germen de una educación intergeneracional.

Finalizada la entrevista, se aplica la técnica del TIC-TAT(Kachinovsky y Martínez, 2013). En una de las láminas presentadas para que los niños construyan historias se pone en cuestión una escena de tipo colaborativo, en tanto ambos personajes comparten un único objeto, la laptop. Su peculiaridad consiste en proponer un encuentro entre un adulto mayor y un niño o niña, que fácilmente provoca asociaciones en torno al vínculo abuelo - nieto/nieta. Un recorte del relato brindado por Victoria resulta elocuente, si se piensa al dispositivo tecnológico como mediador del acto de conocimiento y del vínculo educativo: "Capaz que él le está preguntando algo, que está viendo lo que ella hace; le está preguntando a ella o él que le esté mostrando algo a ella. Pueden ser las dos cosas". Ambos ocupan, en forma indistinta, la posición de enseñantes. El uso del gerundio - "preguntando", "mostrando"- apuntala la hipótesis de proceso, no de escenario clausurado e inmodificable.

La entrevista previene de la tentación a trazar un camino imaginario sin tropiezos ni retrocesos, afín a una idealización de la tecnología plena de ingenuidad, cuando en otros momentos, incluso frente a esta misma lámina, Victoria asume un camino regresivo según el cual el saber es propiedad del otro: "Capaz que [el abuelo] le está enseñando a mandar un mensaje, un mail". Por otra parte, en el psiquismo humano lo heterogéneo suele ser el mejor de los escenarios.

\section{Reflexiones finales}

El análisis de la entrevista con Victoria ha puesto de relieve el impacto del Plan CEIBAL en su vida escolar y en el conjunto de condicionantes personales e institucionales que lo han hecho posible. Se detectan asimismo algunas dimensiones y subdimensiones de análisis que participan y subjuntivizan la relación con el saber. Se ha logrado visualizar la alternancia de posiciones subjetivas y relativas en el eje saber - no saber, elucidándose algunos engranajes que permiten entender el proceso de tránsito entre una posición y otra. Entre ellos cabe destacar: 
a) La importancia del otro singular (semejante): deseo del otro/otros significativo/s (figuras parentales o sustitutos); potencia docente, cuando además de cumplir con su función de enseñante se constituye en un operador subjetivante; cadena de mediadores entre el saber y Victoria.

b) La importancia del otro colectivo (nivel institucional): centro educativo, políticas educativas, políticas sociales en general.

c) Los requisitos de orden psíquico: función de reconocimiento (ser investida por el otro como sujeto de conocimiento); identificación con los ideales del otro significativo; construcción del deseo de saber cual proceso de apropiación y diferenciación del deseo del otro; condiciones de estabilidad del entorno familiar concomitante al sentimiento de continuidad existencial.

En cuanto a las proyecciones de este tránsito o proceso, se identifican dos escenarios pasibles de ser afectados:

a) A nivel individual, no se distingue una influencia decisiva sobre el proyecto de vida, al menos en el caso estudiado.

b) A nivel familiar, el impacto del Plan CEIBAL sobre la R/S se manifiesta con más fuerza, dando lugar a lo que se conoce como educación intergeneracional.

A este esquema es preciso agregar otros hallazgos. Se detecta, por ejemplo, un incremento de lo intersubjetivo y lo colaborativo a punto de partida de una maestra que jerarquiza el dispositivo tecnológico en el trabajo pedagógico diario. Tal incremento no se limita al espacio aula y se extiende al ámbito familiar. En ambos lugares se observan frecuentes intercambios humanos en los que el conocimiento actúa como mediador del vínculo. Se asiste así a una facilitación del pasaje de lo intersubjetivo a lo intrasubjetivo, evidencia empírica de los postulados vygotskianos. La entrevista pone de manifiesto que el Plan CEIBAL y sus dispositivos tecnológicos requieren de una red o cadena de mediadores humanos, cuya conjunción hacen de CEIBAL una disponibilidad personal. Las palabras de Victoria refutan nuevamente la falacia según la cual la máquina podría desplazar al semejante (Kachinovsky et al., 2013). En cambio, es preciso concebir la configuración de una red de apuntalamientos recíprocos que sostienen el cambio actitudinal en Victoria, una suerte de círculo virtuoso en torno al saber. Algunos segmentos de esta red se presentan del siguiente modo:

- políticas educativas $\leftrightarrow$ centro educativo;

- centro educativo $\leftrightarrow$ maestra de clase; 
- maestra de clase $\leftrightarrow$ Victoria;

- maestra de clase $\leftrightarrow$ madre adoptiva;

- maestra de clase $\leftrightarrow$ padre adoptivo;

- familia $\leftrightarrow$ Victoria.

Uno de los hallazgos más sustantivos de esta entrevista se relaciona con el papel que parece cumplir la ceibalita respecto al lenguaje, en el sentido de favorecer un aumento del surtido lexical de Victoria. Si bien se mantienen algunas características propias del código restringido (Bernstein, 1988 y 1989), se advierten indicios de una incipiente relación con el lenguaje de carácter más familiar. En virtud de esta circunstancia y de las evidencias recogidas es posible proponer a título de hipótesis que la ceibalita estaría operando como una nueva oportunidad, es decir, como un nuevo "baño de palabras" para el caso en cuestión. Surge entonces la necesidad de preguntarse si cumplirá esta función también en otros niños y jóvenes.

En síntesis, un complejo conjunto de variables, con frecuencia interdependientes, compromete los procesos psíquicos en juego: la función de reconocimiento, la construcción del deseo de saber, el proceso de apropiación del deseo del otro, los modos de incorporación o asimilación de nuevos conocimientos (la tecnología en este caso), la incidencia del contexto familiar (precipitación de circunstancias personales en este caso); la particular tramitación de crisis vitales y existenciales. Es difícil determinar, no obstante, el peso relativo de cada uno de los factores mencionados sobre el aprendizaje.

Finalmente, y aunque pueda resultar demasiado obvio, se confirma una vez más en Victoria que la accesibilidad a la tecnología depende de múltiples factores o variables que deben solidarizarse entre sí para que ello sea posible, variables en las que siempre están los otros comprometidos: los representantes del poder político, las autoridades educativas, el centro escolar y sus maestros, la familia, los pares. La ceibalita desembarcó en la escuela de Victoria bastante antes de que ella llegara a sexto año, y es recién allí cuando se produce este antes y después de CEIBAL que invita a celebrar con renovadas expectativas la apuesta uruguaya. 


\section{Referencias bibliográficas}

Aulagnier, P. (1977). La violencia de la interpretación. Del pictograma al enunciado. Buenos Aires: Amorrortu.

Bajtín, M. M. (1990). Estética de la creación verbal (4a ed.). México: Siglo XXI.

Beillerot, J. (1996). La formación de formadores. Buenos Aires: Novedades Educativas.

Bernstein, B. (1988). Clases, códigos y control II. Hacia una teoría de las transmisiones educativas. Madrid: Akal.

Bernstein, B. (1989). Clases, códigos y control I. Estudios teóricos para una sociología del lenguaje. Madrid: Akal.

Bruner, J. (1991). Actos de Significado. Más allá de la revolución cognitiva. Madrid: Alianza.

Celener, G. y Guinzbourg, M. (2009). El cuestionario desiderativo, $6^{\mathrm{a}}$ ed. Buenos Aires: Lugar.

Cisterna, F. (2005). Categorización y triangulación como procesos de validación del conocimiento en investigación cualitativa. Theoría, 14(1), 61-71.

De Sousa Santos, B. (2010). Descolonizar el saber, reinventar el poder. Montevideo: Trilce Extensión universitaria. Universidad de la República.

Exclusión, pobreza y TIC en las escuelas de América Latina y España (2015-16). Recuperado de https://sites.google.com/site/exclusionpobrezaticamlat/

Enriquez, E. (1993). El sujeto humano: de la clausura identitaria a la apertura al mundo. En Dorey, R., Castoriadis, C., Enriquez, E., Thom, R., Ménéchal, J. Fridman, W. H. Green, A. El inconsciente y la ciencia (pp. 51-80). Buenos Aires: Amorrortu.

Foucault, M. (1992). Microfísica del poder. Madrid: La Piqueta.

Green, A. (1996). La metapsicología revisitada. Buenos Aires: Eudeba.

Kachinovsky A., Dibarboure M., Paredes-Labra J. (2017). Plan Ceibal e inclusión social. Un caso paradigmático. Psicología, Conocimiento y Sociedad, 7(2), 64-85. Disponible en: https://bit.ly/2BYRriz

Kachinovsky, A. (2016). El cuento infantil como objeto intermediario para el psiquismo. Investigaciones en Psicología (2016, 21, 1), pp. 35-44. Buenos Aires: UBA.

Kachinovsky, A. et al. (2013). Impacto de Plan CEIBAL en el funcionamiento cognitivo y lingüístico de los niños. En: Rivoir, A. (Coord.). Plan CEIBAL e inclusión social: perspectivas interdisciplinarias (pp. 99-152). Montevideo: Plan CEIBAL-Universidad de la República.

Kachinovsky, A. y Martínez, S. (2013). En: Kachinovsky, A. y Muñiz, M. (Eds.). Itinerarios de la Psicología Clínica. Avances, notas y encuentros de norte a sur, pp. 145-189. Monterrey: Universidad Autónoma de Nuevo León.

Kazez, R. (2009). Los estudios de casos y el problema de la selección de la muestra: aportes del sistema de matrices de datos. Subjetividad y procesos cognitivos, 13(1), 71-89. Recuperado de https://bit.ly/2Sdfi3D

Laplanche, J. (1996). La prioridad del otro en psicoanálisis. Buenos Aires: Amorrortu. 
López de Caiafa, C. (1989). Aproximación a la castración en la obra de Melanie Klein. En: La castración. Freud - Klein - Lacan, pp.73-98. Montevideo: EPPAL.

Murray, H. (1979). Test de Apercepción Temática (TAT) Manual para la aplicación, $4^{a}$ ed. Buenos Aires: Paidós.

Ogden, T. (1992). La frontera primaria de la humana experiencia. Madrid: Julián Yebenes.

Prol, G. (2004). La escritura y la clínica psicopedagógica. En: Schlemenson, S. (Ed.), Subjetividad y lenguaje en la clínica psicopedagógica (pp. 75-97). Buenos Aires: Paidós.

Ricoeur, P. (1996). Sí mismo como otro. Madrid: Siglo XXI.

Sánchez-Antolín, P. y Paredes-Labra, J. (2014). La concreción de las políticas educativas de integración de las TIC europeas y españolas en la Comunidad de Madrid. Teoría de la educación. Educación y cultura en la sociedad de la información/Education in the knowledge society, 15(4), 106-133.

Sen, A. (2000). Desarrollo y libertad. Barcelona: Planeta.

Sen, A. (1992). Inequality Reexamined. Oxford: Oxford University Press.

Stake, R. (2005). Qualitative case studies (3a ed.). En: Denzin, N. y Lincoln, Y. (Eds.). Handbook of qualitative research (pp. 443-466). London: Sage.

Stake, R. (2007). Investigación con estudio de caso (4a ed.). Madrid: Morata.

Tedesco, J. C. (2014). Tecnologías de la información y desigualdad educativa en América Latina. Archivos Analíticos de Políticas Educativas, 22(48).

http://dx.doi.org/10.14507/epaa.v22n48.2014.

Vaillant, D. (2013). Las políticas TIC en los sistemas educativos de América Latina: Caso Uruguay. Recuperado de https://bit.ly/2TdLEzW\# 